\title{
К ВОПРОСУ ДИАГНОСТИКИ РИСКОВ ВЫСШЕГО ОБРАЗОВАНИЯ В КОНТЕКСТЕ ДИСТАНЦИОННОГО ОБУЧЕНИЯ
}

\section{(c) 2020 Каржанова Наталья Викторовна}

кандидат филологических наук, доцент, кафедра иностранных языков № 3 Российский экономический университет им. Г. В. Плеханова, Россия, Москва E-mail: knatalya11@mail.ru

\section{(c) 2020 Соколова Екатерина Иосифовна}

кандидат филологических наук, доцент, кафедра иностранных языков № 3 Российский экономический университет им. Г. В. Плеханова, Россия, Москва E-mail:kafmkk@mail.ru

\section{(c) 2020 Тарарина Лариса Игоревна}

кандидат педагогических наук, доцент, кафедра лингвистики и перевода Российский государственный социальный университет, Россия, Москва E-mail: it31@mail.ru

\section{(c) 2020 Адасова Яна Борисовна}

преподаватель, кафедра иностранных языков № 3

Российский экономический университет им. Г. В. Плеханова, Россия, Москва E-mail: adasova_yana@rambler.ru

В статье авторов рассматривается и анализируется достаточно проблемный вопрос диагностики рисков высшего образования в контексте дистанционного обучения, обозначенного влиянием наступившей мировой пандемии. Объектом исследования выступила система высшего образования в Российской Федерации, а предметом - диагностика рисков данного образования в контексте вынужденной активизации дистанционного обучения студентов. Теоретическое и методологическое значение исследования заключены в развитии теории и методологии диагностики и управления рисками в высшем образовании (в частности развитием классификации рисков, методов их определения и оценки). Практическое значение проведенного авторами исследования определяется полученными результатами количественного анализа рисков высшего образования в Российской Федерации в аспекте обучения студентов по дистанционному формату.

Ключевые слова: Вопрос, диагностика, риск, высшее образование, контекст, обучение, дистанционное обучение, высшее учебное заведение.

Дистанционный формат работы в условиях мировой пандемии коронавирусной инфекции становится доминирующим и, зачастую, единственно оправданным и безопасным для социума форматом [8] во многих областях экономики, связанных со скоплением большого количества людей во всех развитых странах. Не является исключением здесь и высшее образование.

Согласно данным ряда мировых консалтинговых компаний $[5,6,8]$ в первой половине 2020 года дистанционный формат обучения $[4$, с. 55] в том или ином виде стал преобладать у чуть менее половины всех высших учебных заведений (в среднем такая ситуация наблюдалась у порядка 41,8 процента от совокупного количества высших учебных заведений). Для сравнения в
2019 году среднее значение данного показателя составляло лишь 3,3 процента, а в 2018 году лишь 3,1 процента. При этом следует отметить, что до 2018 года включительно среднее значение анализируемого показателя не поднималось выше 3 процентов и находилось в интервале от 2,3 до 2,5 процентов включительно (рис. 1). В основном к такой форме обучения до 2020 года прибегали учреждения [7], специализирующиеся на работе в заочном формате [1, с. 357] или высшие учебные заведения, использующие инновационные технологии (например, различные онлайн-университеты).

Кризисный формат работы [8] высших учебных заведений в Российской Федерации существенным образом отразился и на уровне 


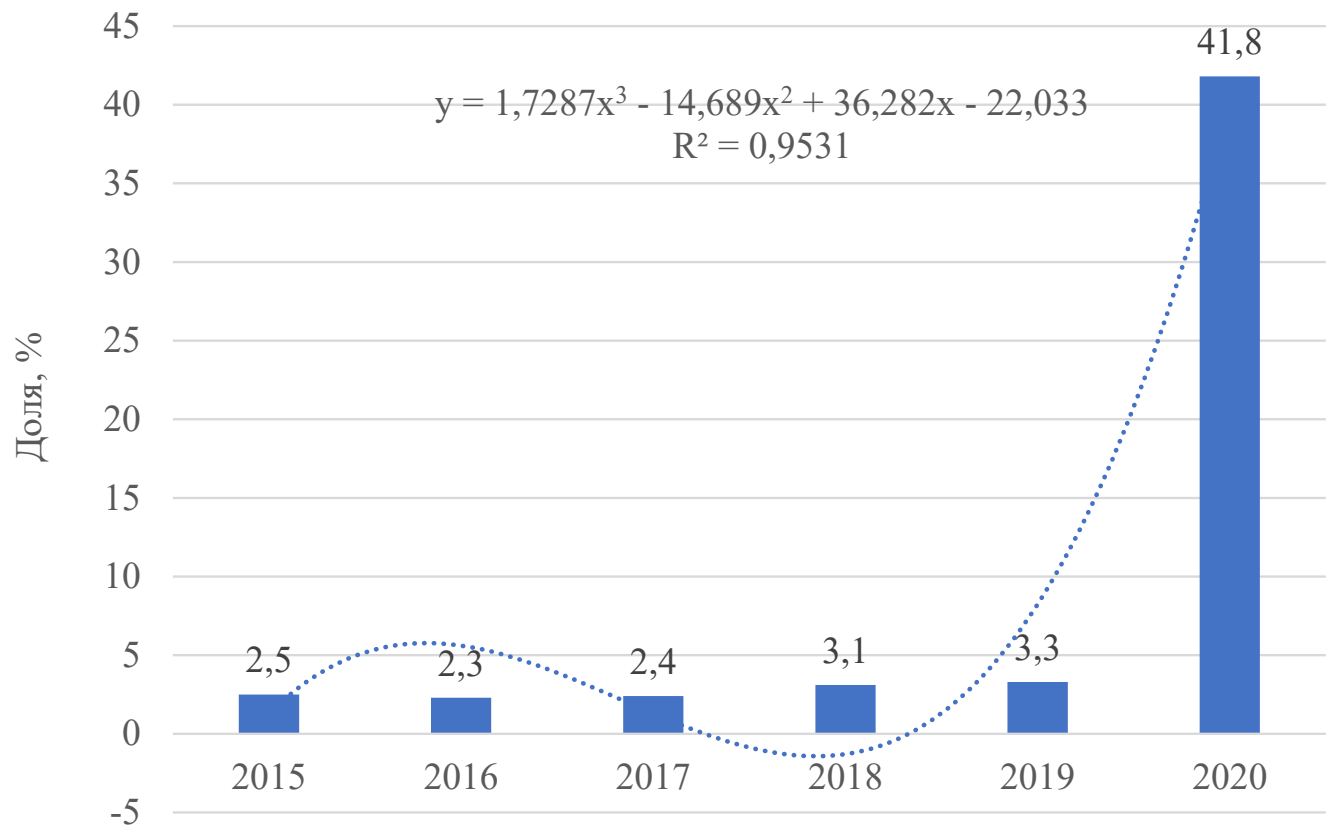

Годы

Puc. 1. Доля высших учебных заведений в Российской Федерации, использующих в 2015-2020 годах дистанционный формат обучения, как преимущественный

рисков, свойственных данному виду экономической деятельности, средний уровень которых в первой половине 2020 года увеличился относительно 2019 года более чем в три раза, составив колоссальные 37,5 процента (рис. 2). До 2020 года максимальный уровень риска имел место в 2017 году и составлял 13,6 процента. В оставшиеся временные интервалы значение анализируемого показателя не поднималось выше 12,8 процентов (средний уровень 2018 года) и не опускалось ниже 11,9 процентов (средний уровень 2016 года). В целом с 2015 по 2020 годы средний уровень рискованности деятельности высших учебных заведений в Российской Федерации увеличился в 3 раза ровно. По прогнозу средний уровень анализируемого показателя за вторую половину 2020 года, исходя из текущего состояния событий на октябрь месяц, может подняться еще на 3,8 процента.

Исходя из того, что деятельность высших учебных заведений в Российской Федерации в 2020 году была связана с гораздо большими рисками, чем ранее, применяемые в настоящее время подходы к их диагностике [2, с. 199], на наш взгляд, уже не являются достаточно эффективными.

В подтверждение указанного вывода приведем полученные нами данные по проблемно- сти диагностики рисков высшего образования в Российской Федерации в ретроспективе и в контексте мировой пандемии 2020 года (первая половина с января по июнь) с акцентом на дистанционное обучение студентов (рис. 3). Как видно ниже, концентрация проблем в проведении диагностики рисков за анализируемый период времени имела пик в правой части диаграммы, а именно, в первой половине 2020 года. Здесь уровень проблемности возрос более чем в два раза (48,9 процента против 21,8-24,9 процента), относительно величин за 2015-2019 годы. Составленный прогноз показателя на вторую половину 2020 года свидетельствует о продолжении его увеличения до не менее чем до 53,6 процента.

Снизить проблемность диагностики рисков высшего образования в Российской Федерации $[3,6]$ в будущих периодах времени можно, на наш взгляд, за счет использования: более совершенного инструментария, основанного, в том числе на автоматизированных программных продуктах, нейронных сетях и эвристике; повышении квалификации персонала, ответственного за проведение диагностики; более глобальной формализации алгоритмов, включенных как в методику, так и методологию проводимой диагностики.

Таким образом, можно сделать вывод, что 


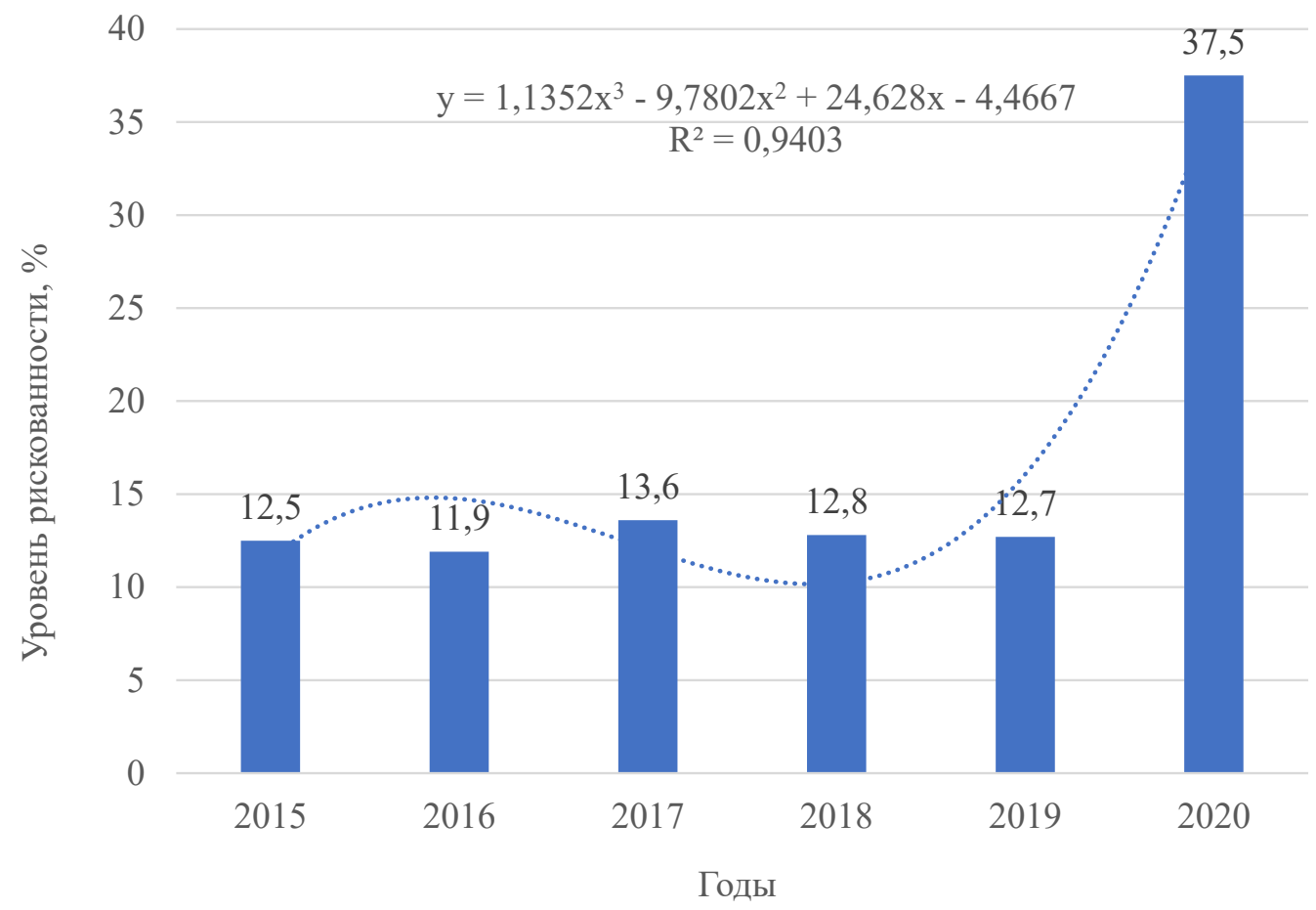

Puc. 2. Средний уровень рискованности деятельности высших учебных заведений в Российской Федерации в 2015-2020 годах

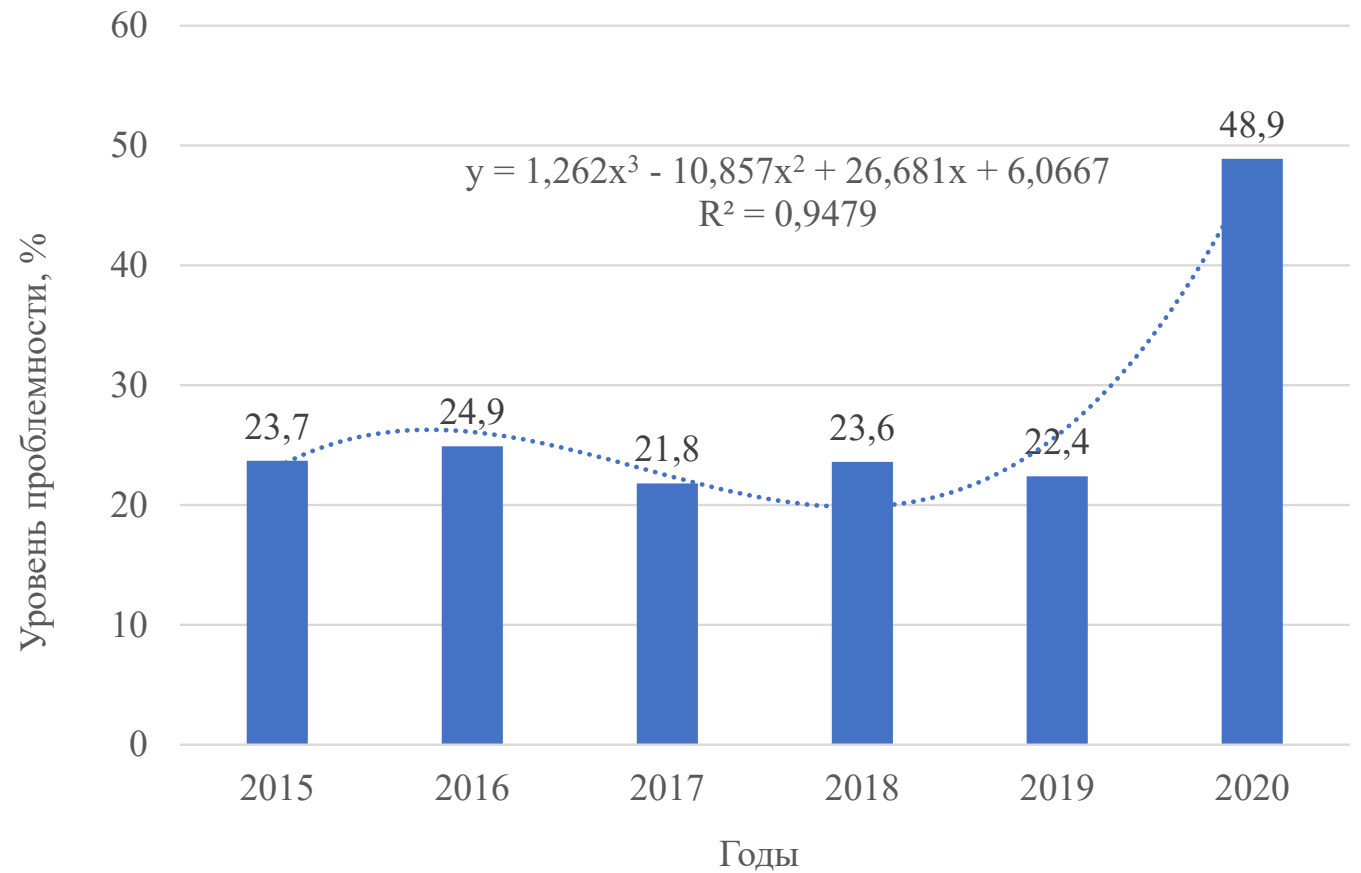

Puc. 3. Статистические данные по проблемности диагностики рисков высшего образования в Российской Федерации за 2015-2020 годы 
контекст дистанционного обучения в высших учебных заведениях Российской Федерации, обусловленный возникновением в начале 2020 года мировой пандемии коронавирусной инфекции наложил в определенной мере ярко негативный отпечаток на высшее образование в целом и на вопрос (до обозначенного периода протекание процессов проходило в достаточной мере по устоявшейся тенденции) диагностики его рисков в частности.

Так, исходя из существенно возросшей доли высших учебных заведений, применяющих дистанционный формат работы (с 2,5 процентов в 2015 году до 41,8 процентов в первой половине 2020 года) и среднего уровня рискованности их деятельности (с 12,5 процентов в 2015 году до 37,5 процентов в первой половине 2020 года) су- щественно возросла проблемность диагностики рисков (с 23,7 процентов в 2015 году до 48,9 процентов в первой половине 2020 года).

Для разрешения данной проблемы, на наш взгляд, целесообразно модернизировать как уже применяемые инструменты диагностики (их необходимо адаптировать в первую очередь под усложненные неопределенностью условия внешней и внутренней среды) так и внедрить и начать использование новые более перспективные инструменты (нейронные сети, эвристику и автоматизированные программные продукты). Также акцент необходимо сделать на повышении квалификации персонала, ответственного за ключевые процессы и глобальной формализации алгоритмов диагностики по методической и методологической составляющей.

\section{Библиографический список}

1. Кац И. И., Лесевицкий А. В. Дистанционная форма обучения: доводы «за» и «против» / И. И. Кац, А. В.Лесевицкий // Формирование гуманитарной среды в вузе: инновационные образовательные технологии. Компетентностный подход - Пермь: Изд-во: «Пермский национальный исследовательский политехнический университет», 2019.- № 1.- С. 355-358.

2. Лялюк А. В. Моделирование и диагностика рисков образовательной среды на основе математических методов / А. В. Лялюк // Проблемы современного образования - Москва: Изд-во «Московский педагогический государственный университет», 2019.- № 2.- С. 198-204.

3. Платонова Е. Д., Мусарский М. М., Чжан Тяньхуэй Экспортные возможности российских вузов в свете реализации национальных проектов / Е. Д. Платонова, М. М. Мусарский, Тяньхуэй Чжан // Экономические науки Москва: Изд-во: «ООО «24 Принт», 2019.- № 12.- С. 44-49.

4. Шатуновский В. Л., Шатуновская Е. А. Ещё раз о дистанционном обучении (организация и обеспечение дистанционного обучения) / В.Л. Шатуновский, Е.А. Шатуновская // Вестник науки и образования - Иваново: Изд-во: «Олимп», 2020.- № 9-1.- С. 53-56.

5. Компания «ЛАНИТ» [Электронный ресурс]: аналитические материалы - Официальный сайт компании «ЛАНИТ», 2020.- Режим доступа: https://www.lanit.ru/

6. Компания «Сбер Решения» [Электронный ресурс]: аналитические материалы - Официальный сайт компании «Сбер Решения», 2020.- Режим доступа: https://sber-solutions.ru/

7. Компания «Федеральная служба государственной статистики» [Электронный ресурс]: аналитические материалы - Официальный сайт компании «Федеральная служба государственной статистики», 2020. - Режим доступа: https://rosstat.gov.ru/

8. Компания «HLB Russian Group» [Электронный ресурс]: аналитические материалы - Официальный сайт компании «HLB Russian Group», 2020.- Режим доступа: https://www.hlbrus.ru/ 